\title{
Unmet Health Need Among Roma: Visual Acuity and the Use of Vision Correcting Aids in the Hungarian Roma Population
}

\section{Gergely Losonczy}

Department of Ophthalmology, Donders Institute for Brain, Cognition and Behaviour, Radboud University Medical Center, Nijmegen, The Netherlands

\section{Peter Piko}

MTA-DE Public Health Research Group, Department of Public Health and Epidemiology, Faculty of Medicine, University of Debrecen, Debrecen, Hungary.

\section{B. Jeroen Klevering}

Department of Ophthalmology, Donders Institute for Brain, Cognition and Behaviour, Radboud University Medical Center, Nijmegen, The Netherlands

\section{Zsigmond Kosa}

Department of Methodology for Health Visitors and Public Health, Faculty of Health, University of Debrecen, Nyiregyhaza, Hungary.

\section{Janos Sandor}

Department of Public Health and Epidemiology, Faculty of Medicine, University of Debrecen, Debrecen, Hungary.

\section{Roza Adany ( $\nabla$ adany.roza@med.unideb.hu )}

MTA-DE Public Health Research Group, Department of Public Health and Epidemiology, Faculty of Medicine, University of Debrecen, Debrecen, Hungary.

\section{Research Article}

Keywords: Unmet health, Roma, Visual acuity, vision correcting aids, Hungarian Roma population, ethnic minority group, Europe, eye examination, mutations

Posted Date: January 6th, 2022

DOI: https://doi.org/10.21203/rs.3.rs-1226286/v1

License: () (1) This work is licensed under a Creative Commons Attribution 4.0 International License. Read Full License 


\section{Abstract}

The Roma population is the largest transnational ethnic minority group in Europe often facing socioeconomic inequalities and various health problems. In the present study we investigated the visual acuity and its affecting factors along with spectacle use of the Roma in comparison with the general population in Hungary.

A cross-sectional survey was carried out including 832 participants aged 20 to 64 years. We recorded the visual acuity, anthropometric, demographic, socioeconomic and health-related data of each individual.

Although the average uncorrected visual acuity was somewhat higher, the use of a visual aid was significantly less frequent in the Roma population, especially in the group with a visual acuity below 0.5 in both eyes $(14.3 \%$ vs $77.1 \%, \mathrm{p}<0.001)$. Age, abdominal obesity and disturbances of the carbohydrate metabolism had a negative impact on visual acuity in both populations, however, the latter was a much stronger risk factor in the Roma population (OR: 5.789, 95\% Cl: 2.239-14.964, $\mathrm{p}<0.001$ ) than in the general population (OR: $2.075,95 \% \mathrm{Cl}: 1.097-3.926, \mathrm{p}=0.025)$.

Our results show serious unmet health needs within the Roma population, which calls for public health programs to improve poor primary care indicators on regular eye examination, and a much more rigorous diabetes control.

\section{Introduction}

The European Roma population moved from South Asia into Europe between the 9th and 14th centuries. Nowadays they from the largest transnational ethnic minority group in Europe with a population of about 10-12 million people ${ }^{1}$. Most of the European Union`s Roma population lives in Eastern-European countries including Romania, Bulgaria, Hungary and Slovakia where they make up between 5 and 10 per cent of the population, but there are also sizeable Roma minorities in the Western Balkan countries, as well as in Spain, Italy, France and the $\mathrm{UK}^{2-4}$. In comparison with the general populations, Roma populations have poorer health and high burden of both communicable and non-communicable diseases $^{5-13}$, which can be attributed to social exclusion negatively influencing their access to educational, social and health services ${ }^{14,15}$.

A diminished visual function can deeply affect quality of life, social participation and economic opportunity. Vision impairment also carries a high financial cost for health care services. Vision and hearing impairment have been associated with a greater risk of injuries, loss of functional activity, anxiety and depression ${ }^{16-20}$. It has been shown, that minority ethnic groups such as Blacks and South Asians in England $^{21}$ and American Chinese people in the US have a higher prevalence of visual impairment compared to White people $\mathrm{e}^{22,23}$, and have less access to appropriate health care services and treatments.

The only data available on the visual function of Roma people as compared to the general population comes from a study conducted in Spain. The Roma population was more likely to present with vision 
limitations for both far and near sights and showed a lower use of corrective aids than the general population. These findings were associated with poor mental health and lower social participation ${ }^{24}$. The position of Roma on the labour market is very unfavourable ${ }^{25}$, and their integration is not only a moral, but also an economic imperative in the European Union with workforce shortages ${ }^{26}$. Among measures to overcome labour market barriers faced by Roma exploring and fulfilling their unmet health needs is of crucial importance.

In the framework of a complex (behavior and health) survey as part of physical examination we investigated the visual acuity and spectacle dependence of the Hungarian Roma in comparison with the general population. The aim of the current study was to define uncorrected visual acuity and the use of glasses and/or contact lenses in Roma compared to the Hungarian population. We also investigated the effect of demographic, socioeconomic and health parameters on the visual acuity in these groups.

\section{Materials And Methods}

In 2018, we performed a cross-sectional survey in two North-East Hungarian counties (Hajdú-Bihar and Szabolcs-Szatmár-Bereg) where the majority of Roma live, frequently in segregated colonies ${ }^{27}$. This study had three main pillars as questionnaire-based, physical, and laboratory investigations involving adults aged 20-64 years from the Hungarian general (HG) and Hungarian Roma (HR) populations. Altogether, 832 participants were randomly selected including 417 HG (185 male and 232 female) and 415 HR (108 male and 307 female) subjects. Details of sampling, data collection and management are thoroughly described elsewhere ${ }^{28}$. In brief, segregated colonies exceeding 100 inhabitants were identified previously by Roma field workers and ethnicity of the colony population was assessed by self-declaration. After verification of a previously created database, twenty colonies were randomly chosen, and twenty-five households were randomly drawn from each colony. Individuals aged 20 to 64 years were identified in each Roma household and eventually one person was selected by random table. Individuals, aged 20 to 64 years, living in private households and registered by general practitioners in the same counties, were randomly chosen from the General Practitioners' Morbidity Sentinel Stations Program's registry (which has been working continuously since 1998) and served as reference sample ${ }^{29}$. In addition to anthropometric (among them waist circumference), demographic (age, sex), socioeconomic (among them educational level), and health-related data (as prevalence of hypertension, diabetes, antihypertensive, anti-diabetic and lipid-lowering treatments), fasting blood samples (native and EDTAanticoagulated) were also collected for routine laboratory tests including - among others - fasting glucose, high-density-lipoprotein-cholesterol (HDL-C), triglyceride (TG) measurements. As it is previously described in detail for the definition of metabolic syndrome the following physical and laboratory parameters were considered as abnormal by adopting the International Diabetes Federation's cut-off values: waist circumference: $\geq 94 \mathrm{~cm}$ for males and $\geq 80 \mathrm{~cm}$ for females; systolic BP of $\geq 130 \mathrm{mmHg}$ and/or diastolic BP of $\geq 85 \mathrm{mmHg}$; fasting glucose level: $\geq 5.6 \mathrm{mmol} / \mathrm{L}$; fasting triglyceride level: $\geq 1.7$ $\mathrm{mmol} / \mathrm{L}$; fasting high-density cholesterol (HDL-C) level: $<1.03 \mathrm{mmol} / \mathrm{L}$ in males and $<1.29 \mathrm{mmol} / \mathrm{L}$ in females ${ }^{30}$. 
As part of the physical examination pillar of the survey, we measured the uncorrected visual acuity (UCVA) with the use of standard decimal visual acuity charts in general practitioners' offices on Roma $(n=314)$ individuals, and compared the findings to data obtained on subjects representing the Hungarian general population $(n=395)$. Decreased UCVA was defined as below 0.5 . The use of spectacles or contact lenses was recorded in the questionnaire-based pillar of the study.

Statistical analysis. All statistical tests were performed using IBM SPSS (version 26, IBM Company, Armonk, NY, USA) software. Prevalence data obtained in the survey were compared by $\chi 2$ test. Multivariate linear and logistic regression analyses were applied to examine relationship between visual acuity and relevant demographic (education - in binary logistic model as education level is higher or not than primary one, sex) and health parameters (blood lipid levels, abdominal obesity, fasting glucose level and/or anti-diabetic treatment, blood pressure and/or anti-hypertensive treatment). In generally, the conventional $p$ value of 0.05 was applied.

Ethics declarations. All procedures performed in studies involving human participants were carried out by the ethical standards of the institutional and national research committee and with the 1964 Helsinki declaration and its later amendments. This study was approved by the Ethical Committee of the University of Debrecen, Medical Health Sciences Centre (reference No. 2462-2006), and by the Ethics Committee of the Hungarian Scientific Council on Health (reference No. 61327-2017/EKU). All participants provided written informed consent to participate in the study. This article does not contain any studies with animals performed by any of the authors.

\section{Results}

Main characteristics of the study populations. Age and sex characteristics along with educational level of the study populations and prevalence of components of metabolic syndrome among them are summarized in Table 1. Only subjects with full records were considered in the analysis. 
Table 1

Main characteristics of the Hungarian general (HG) and Roma (HR) populations by sex.

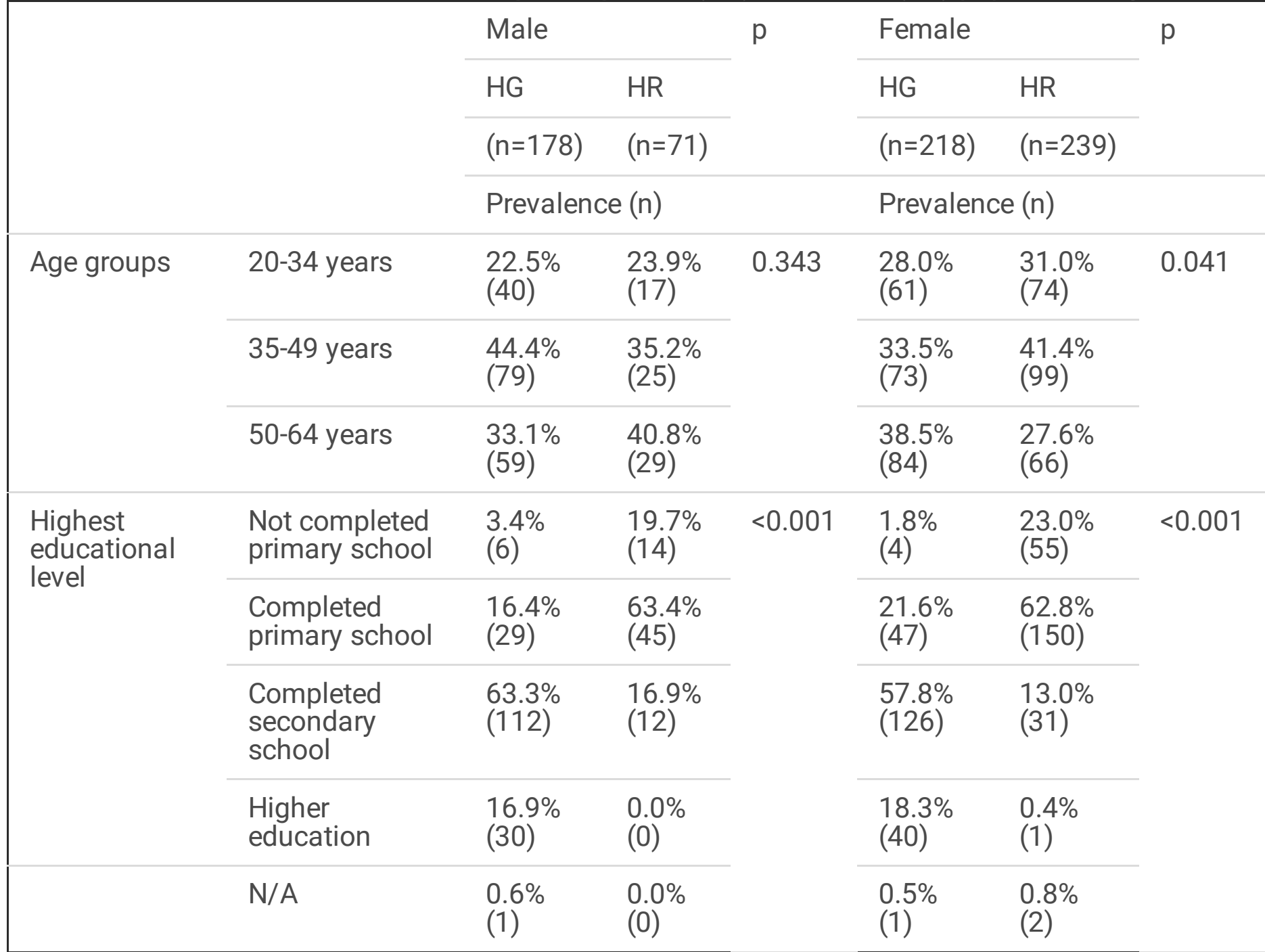

Uncorrected visual acuity. The average uncorrected visual acuity (UCVA) of all eyes was $0.92(95 \% \mathrm{Cl}$ : 0.88-0.96) in the Hungarian general and 1.03 (95\% Cl: 0.99-1.08) in the Hungarian Roma population indicating a statistically significant difference $(p=0.001)$ between them. However, it is important to notice that no significant difference was measured in the proportion of eyes with a decreased uncorrected visual acuity defined as UCVA below 0.5 in the two groups. (Table 2.) 
Table 2

Average uncorrected visual acuity $(A)$ and the prevalence of severely decreased visual acuity (defined as UCVA 0.5$)(B)$ in the Hungarian general and Roma populations by sex.

\begin{tabular}{|c|c|c|c|c|c|c|c|c|}
\hline \multirow[t]{3}{*}{ A } & \multicolumn{4}{|c|}{ Male } & \multirow[t]{3}{*}{ p-value } & \multicolumn{2}{|l|}{ Female } & \multirow{3}{*}{$\begin{array}{l}\mathrm{p}- \\
\text { value }\end{array}$} \\
\hline & \multicolumn{2}{|l|}{ HG } & \multicolumn{2}{|c|}{ HR } & & HG & HR & \\
\hline & \multicolumn{4}{|c|}{ Average $(95 \% \mathrm{Cl})$} & & \multicolumn{2}{|c|}{ Average $(95 \% \mathrm{Cl})$} & \\
\hline Left eye & \multicolumn{2}{|c|}{$\begin{array}{l}0.93(0.87- \\
0.98)\end{array}$} & \multicolumn{2}{|c|}{$1.14(1.04-1.24)$} & 0.001 & $\begin{array}{l}0.91(0.86- \\
0.96)\end{array}$ & $\begin{array}{l}1.01(0.96- \\
1.07)\end{array}$ & 0.004 \\
\hline $\begin{array}{l}\text { Right } \\
\text { eye }\end{array}$ & \multicolumn{2}{|c|}{$\begin{array}{l}0.94(0.88- \\
0.99)\end{array}$} & \multicolumn{2}{|c|}{$1.08(0.98-1.19)$} & 0.052 & $\begin{array}{l}0.91(0.86- \\
0.96)\end{array}$ & $\begin{array}{l}1.00(0.95- \\
1.06)\end{array}$ & 0.011 \\
\hline $\begin{array}{l}\text { Both } \\
\text { eyes }\end{array}$ & \multicolumn{2}{|c|}{$\begin{array}{l}0.93(0.88- \\
0.99)\end{array}$} & 1.1 & $.21)$ & 0.009 & $\begin{array}{l}0.91(0.86- \\
0.96)\end{array}$ & $\begin{array}{l}1.01(0.95- \\
1.06)\end{array}$ & 0.012 \\
\hline \multirow[t]{2}{*}{ B } & & \multicolumn{2}{|l|}{ HG } & \multicolumn{2}{|l|}{$\mathrm{HR}$} & \multirow[t]{2}{*}{$p$-value } & & \\
\hline & & \multicolumn{4}{|c|}{ Prevalence (n) } & & & \\
\hline \multicolumn{2}{|c|}{ Left eye $<0.5$} & 10. & 43) & \multicolumn{2}{|c|}{$8.7 \%(27)$} & \multicolumn{2}{|l|}{0.343} & \\
\hline \multicolumn{2}{|c|}{ Right eye $<0.5$} & \multicolumn{2}{|c|}{$10.4 \%(41)$} & $10.0^{\circ}$ & 31) & 0.878 & & \\
\hline \multicolumn{2}{|c|}{ One eye $<0.5$} & \multicolumn{2}{|c|}{$3.5 \%(14)$} & \multicolumn{2}{|c|}{$5.2 \%(16)$} & 0.364 & & \\
\hline \multicolumn{2}{|c|}{ Both eyes $<0.5$} & \multicolumn{2}{|c|}{$8.8 \%(35)$} & \multicolumn{2}{|c|}{$6.8 \%(21)$} & & & \\
\hline
\end{tabular}

The use of visual aids. There was a statistically significant difference in the proportion of people regularly wearing glasses or contact lenses to correct their far sight. There were $23.5 \%$ and $8.9 \%$ of people wearing a vision correction aid in the Hungarian general and Roma population, respectively $(p<0.001)$. The difference was statistically significant for both sexes (male: $21.9 \%$ vs $5.6 \%, p=0.002$; female: $24.9 \%$ vs $9.9 \%, p<0.001)$ in each age group (Table $3 \mathrm{~A})$. These data indicate that the proportion of people in all age and sex groups making use of a visual aid is significantly less frequent in the Hungarian Roma sample as compared to that of the Hungarian general population. The difference in the use of visual aids was independent of the visual acuity. Both in the group of people with one or two eyes with a visual acuity at least 0.5 and in the group of people with a visual acuity below 0.5 on both eyes the number of people using glasses or contact lenses was significantly lower in the Hungarian Roma population as compared with the Hungarian general population. The most striking difference was found in the group with a visual acuity below 0.5 in both eyes $(14.3 \%$ vs $77.1 \%, p<0.001)$ indicating a serious unmet health need in the Hungarian Roma population. (Table 3B.) 
Table 3

Frequency of people using glasses or contact lenses in the Hungarian general $(\mathrm{HG})$ and Roma $(\mathrm{HR})$ populations by age groups $(A)$ and representation of individuals using glasses or contact lenses with uncorrected visual acuity of $\geq 0.5$ vs. $<0.5$ in the Hungarian general $(\mathrm{HG})$ and Roma (HR) populations (B).

\begin{tabular}{|llll|}
\hline A & HG & HR & p-value \\
\cline { 2 - 3 } & \multicolumn{2}{l}{ Prevalence (n) } & \\
\hline 20-34 years & $22.8 \%(23)$ & $4.4 \%(4)$ & $<0.001$ \\
\hline 35-49 years & $17.8 \%(27)$ & $5.6 \%(7)$ & 0.002 \\
\hline $50-64$ years & $31.5 \%(45)$ & $18.9 \%(18)$ & 0.032 \\
\hline B & HG & HR & p-value \\
\cline { 2 - 3 } & Prevalence (n) & \\
\hline Both eyes $\geq 0.5$ & $15.9 \%(55)$ & $8.4 \%(23)$ & 0.006 \\
\hline One eye $<0.5$ & $92.9 \%(13)$ & $18.8 \%(3)$ & $<0.001$ \\
\hline Both eyes $<0.5$ & $77.1 \%(27)$ & $14.3 \%(3)$ & $<0.001$ \\
\hline
\end{tabular}

The effect of different health parameters on visual acuity. We examined the effect of demographic and cardiometabolic risk factors on uncorrected visual acuity using linear regression analysis and found that Roma ethnicity was correlated with a slightly better visual acuity in the whole cohort, while age, abdominal obesity and elevated fasting glucose level and/or anti-diabetic treatment had a negative influence on the visual acuity values in the entire cohort as well as in both populations apart. Female sex was a significant risk factor only among Roma. We could not find any statistically significant correlation between visual acuity values and blood lipid parameters in any of the populations. (Table 4.)

Table 4. Correlation obtained by linear regression analysis between visual acuity* and cardiometabolic risk factors/outcomes as components of metabolic syndrome, as well as demographic characteristics on combined (A), Hungarian general (B) and Roma (C) populations. 


\begin{tabular}{|c|c|c|c|}
\hline A - Combined population & Beta & Std. error & p-value \\
\hline Age & -0.006 & 0.001 & $<0.001$ \\
\hline Roma ethnicity** & 0.092 & 0.033 & 0.006 \\
\hline Female sex ${ }^{\star \star}$ & -0.039 & 0.031 & 0.210 \\
\hline Education level** & 0.005 & 0.017 & 0.784 \\
\hline Abdominal obesity** & -0.100 & 0.034 & 0.003 \\
\hline Reduced HDL-C level** & 0.025 & 0.031 & 0.411 \\
\hline Elevated TG level and/or lipid lowering treatment** & 0.039 & 0.032 & 0.225 \\
\hline Elevated fasting glucose level and/or anti-diabetic treatment** & -0.142 & 0.034 & $<0.001$ \\
\hline Elevated blood pressure and/or anti-hypertensive treatment ** & 0.039 & 0.031 & 0.207 \\
\hline B - Hungarian general population & Beta & Std. error & p-value \\
\hline Age & -0.004 & 0.002 & 0.010 \\
\hline Female sex** & 0.001 & 0.037 & 0.988 \\
\hline Education level** & 0.026 & 0.022 & 0.232 \\
\hline Abdominal obesity** & -0.110 & 0.043 & 0.011 \\
\hline Reduced HDL-C level** & 0.039 & 0.040 & 0.322 \\
\hline Elevated TG level and/or lipid lowering treatment** & 0.014 & 0.040 & 0.729 \\
\hline Elevated fasting glucose level and/or anti-diabetic treatment** & -0.098 & 0.042 & 0.021 \\
\hline Elevated blood pressure and/or anti-hypertensive treatment ** & 0.049 & 0.038 & 0.202 \\
\hline
\end{tabular}




\begin{tabular}{|llll|}
\hline C - Roma population & Beta & Std. error & p-value \\
\hline Age & -0.011 & 0.002 & $<0.001$ \\
\hline Female sex* & -0.131 & 0.055 & $\mathbf{0 . 0 1 8}$ \\
\hline Education level** & -0.031 & 0.026 & 0.228 \\
\hline Abdominal obesity** & -0.066 & 0.055 & 0.234 \\
\hline Reduced HDL-C level** & 0.003 & 0.048 & 0.957 \\
\hline Elevated TG level and/or lipid lowering treatment** & 0.070 & 0.052 & 0.185 \\
\hline Elevated fasting glucose level and/or anti-diabetic treatment** & -0.220 & $\mathbf{0 . 0 5 4}$ & $<0.001$ \\
\hline Elevated blood pressure and/or anti-hypertensive treatment ** & 0.056 & 0.052 & 0.284 \\
\hline *: average visual acuity for both eyes as continuous outcome variable & & \\
\hline$* *$ binary covariate & & & \\
\hline
\end{tabular}

Logistic regression analysis was also used to analyse the effect of demographic and cardiometabolic risk factors on the proportion of people with an uncorrected visual acuity below 0.5 on both eyes. Disturbance of carbohydrate metabolism was the only factor showing any association with UCVA in this analysis. (Table 5.) It is to be noted, that elevated fasting glucose level and/or anti-diabetic treatment was a much stronger risk factor in the Roma population (OR: 5.789, 95\% Cl: 2.239-14.964, $\mathrm{p}<0.001$ ) than in the Hungarian general population (OR: 2.075, 95\% Cl: 1.097-3.926, $p=0.025)$.

Table 5. Correlation obtained by logistic regression analysis between visual acuity* and cardiometabolic risk factors/outcomes as components of metabolic syndrome, as well as demographic characteristics on combined (A), Hungarian general (B) and Roma (C) populations.

\begin{tabular}{|c|c|c|c|}
\hline A - combined population & OR & $95 \% \mathrm{Cl}$ & p-value \\
\hline Age & 1.031 & 1.007-1.055 & 0.011 \\
\hline Roma ethnicity** & 0.860 & $0.484-1.528$ & 0.606 \\
\hline Female sex ${ }^{\star \star}$ & 1.372 & $0.800-2.355$ & 0.250 \\
\hline Education level ${ }^{\star \star}$ & 1.210 & $0.935-1.565$ & 0.147 \\
\hline Abdominal obesity** & 1.334 & $0.692-2.571$ & 0.389 \\
\hline Reduced HDL-C level** & 0.605 & $0.347-1.055$ & 0.077 \\
\hline Elevated TG level and/or lipid lowering treatment*ᄎ & 0.842 & $0.488-1.452$ & 0.537 \\
\hline Elevated fasting glucose level and/or anti-diabetic treatment** & 2.760 & $1.646-4.626$ & $<0.001$ \\
\hline Elevated blood pressure and/or anti-hypertensive treatment ** & 1.166 & $0.664-2.048$ & 0.593 \\
\hline
\end{tabular}




\begin{tabular}{|c|c|c|c|}
\hline B - Hungarian general population & OR & $95 \% \mathrm{Cl}$ & p-value \\
\hline Age & 1.022 & $0.995-1.050$ & 0.111 \\
\hline Female sex** & 1.007 & $0.542-1.870$ & 0.983 \\
\hline Education level** & 1.047 & $0.725-1.511$ & 0.806 \\
\hline Abdominal obesity** & 1.253 & $0.576-2.726$ & 0.570 \\
\hline Reduced HDL-C level** & 0.502 & $0.242-1.040$ & 0.064 \\
\hline Elevated TG level and/or lipid lowering treatment*ᄎ & 1.170 & $0.609-2.251$ & 0.637 \\
\hline Elevated fasting glucose level and/or anti-diabetic treatment** & 2.075 & $1.097-3.926$ & 0.025 \\
\hline Elevated blood pressure and/or anti-hypertensive treatment $* *$ & 1.075 & $0.556-2.076$ & 0.831 \\
\hline
\end{tabular}

\begin{tabular}{|c|c|c|c|}
\hline C - Roma population & OR & $95 \% \mathrm{Cl}$ & p-value \\
\hline Age & 1.064 & 1.015-1.116 & 0.010 \\
\hline Female sex** & 5.369 & $1.283-22.462$ & 0.021 \\
\hline Education level** & 1.434 & $0.999-2.059$ & 0.051 \\
\hline Abdominal obesity** & 1.130 & $0.312-4.096$ & 0.853 \\
\hline Reduced HDL-C level** & 0.768 & $0.297-1.987$ & 0.586 \\
\hline Elevated TG level and/or lipid lowering treatment** & 0.438 & $0.154-1.246$ & 0.122 \\
\hline Elevated fasting glucose level and/or anti-diabetic treatment** & 5.789 & 2.239-14.964 & $<0.001$ \\
\hline Elevated blood pressure and/or anti-hypertensive treatment ** & 1.332 & $0.441-4.021$ & 0.611 \\
\hline \multicolumn{4}{|l|}{ *: average visual acuity for both eyes less than 0.5 or 0.5 and above } \\
\hline **: binary covariate & & & \\
\hline
\end{tabular}

\section{Discussion}

We have conducted a three pillars (questionnaire-based, physical, and laboratory investigations) crosssectional study in the Hungarian general and Roma populations in 2018 in North-East Hungary on samples of randomly selected adults aged 20-64 years. We defined uncorrected visual acuity and the use of glasses and/or contact lenses as well as the effect of demographic, socioeconomic and health parameters on the visual acuity. The only data available on the visual function of Roma came from Spain and showed that this population was more likely to present with vision limitations and showed a lower use of corrective aids than the general population. Contrary to this study, we found that the Hungarian Roma population has a slightly, but significantly better average uncorrected visual acuity in every age and 
sex groups as compared to the Hungarian general population. However, this difference did not translate into a clinically significant difference, as the proportion of people with a visual acuity below 0.5 did not significantly differ in the two populations. It is noteworthy, that educational level was significantly lower in the Roma population in all age groups which could have a great role in their socioeconomic segregation and lower social opportunities. However, association between more years spent in education and myopia as suggested by a previous study ${ }^{31}$ could not be confirmed in the present study as educational level had no statistically significant effect on the visual acuity. We cannot exclude the possibility that refractive parameters in the Roma population are closer to the normal emmetropy which could be a genetically determined characteristic ${ }^{32,33}$. Cultural and social isolation, as well as high level of genetic consanguinity throughout the centuries has led to a certain genetic segregation of Roma populations ${ }^{34-36}$. This is not only characterized by an overload of founder mutations, but also by the lack or decreased frequency of some other pathogenic mutations in these populations. These factors lead to a decreased genetic diversity in the Roma population, but the frequency of rare genetic variants and pathogenic alleles maybe both higher ${ }^{37-39}$ and $\operatorname{lower}^{16,40}$ as compared with the general population.

One of the strongest differences between the two populations was found in the use of vision correcting aids. The use of simple visual aids for distance vision, such as glasses or contact lenses, was significantly lower in members of the Hungarian Roma population. This difference was confirmed in all age and both sex groups. This difference could not be explained through the somewhat better visual acuity measured in the Roma population, because the proportion of eyes with a visual acuity below 0.5 did not significantly differ in the two groups. It is noteworthy, that the largest difference in wearing a vision correction aid was found in the group with a visual acuity below 0.5 with one or both eyes, indicating a serious unmet health need in the Hungarian Roma population. The lack of a proper visual correction in the Roma population may severely contribute to their lower education level, lower social opportunities and lower access to the labor market and finally to their social segregation.

We examined the association of demographic and certain health parameters with the visual acuity. Age, abdominal obesity and elevated fasting glucose level and/or anti-diabetic treatment had a statistically significant negative effect on the visual acuity as a continuous variable. However, when visual acuity was analysed as a binary covariate and decreased visual acuity was defined as vision on both eyes less than 0.5 , the only statistically significant association was found with the elevated fasting glucose level and/or anti-diabetic treatment in both populations. Elevated fasting glucose and/or anti-diabetic treatment was a stronger risk factor among the Roma population than in the Hungarian general population. This is in line with our previous findings indicating that elevated plasma glucose or known type 2 diabetes are significantly more frequent in the Hungarian Roma than in the Hungarian general population and that the proportion of untreated diabetes is very high (53.3\%) in the Roma population ${ }^{41,42}$. Also the proportion of missed glucose check-ups was significantly higher in the Roma than in de Hungarian population ${ }^{43}$. It is worth mentioning that in a comparative analysis the Hungarian general population carried a greater genetic risk for the development of type 2 diabetes mellitus than Roma, but in a combined population model the effect of ethnicity was relatively strong on the development of diabetes (OR: $2.484, p<0.001)^{44}$. 
The prevalence of metabolic syndrome (HG: $39.8 \%$, HR: 44.0\%) and insulin resistance (HG: $42.3 \%$ and HR: $40.5 \%$ ) was - almost equally - very unfavourable in both populations ${ }^{28}$. In our present study there was a trend for people with higher waist circumference to have lower visual acuity as seen in the linear regression analysis using vision acuity as a continuous variable. However, this association could not be verified when using a clinically significant cut-off value (UCVA lower than 0.5 ) and vision was considered as a binary variable. On the other hand, based on the present study one cannot exclude the influence of central obesity on visual acuity in these populations. This should be further investigated, not only because very little is known about this association, but also because the prevalence of abdominal obesity is strongly increasing in the Hungarian Roma population ${ }^{42}$.

In the Roma population female sex was shown to be an independent risk factor for lower visual acuity, however this should be taken into consideration with precaution as the female sex was overrepresented in the Roma sample and this can be seen as a limitation of the study. This cross-sectional survey was based on randomly selected households, and as we described previously in many households, a proportionally higher number of women were at home during the day when most visits took place, and men at work at another location ${ }^{28}$. The Hungarian government quadrupled the budget for public works between 2010 and 2015 for all Hungarian municipalities. This is especially relevant for villages in the North-eastern region of Hungary, where segregated Roma settlements are concentrated and our study was carried out. The majority of workers participating in the programme are men from deprived Roma communities.

Our results suggest a slightly better average uncorrected visual acuity in the Hungarian Roma population but a much lower use of vision aids as well as a stronger negative effect of diabetes on uncorrected visual acuity in comparison with the Hungarian general population. These results call for public health actions for the improvement of poor primary care indicators on regular eye examination ${ }^{45}$, and a much more rigorous diabetes control within the Roma population ${ }^{43}$ in Hungary. These measures could have an important impact on the social integration of Roma people in the Hungarian society.

\section{Declarations}

Data availability. The datasets used in the current study are not publicly available due to privacy/ethical restrictions, but are available from the corresponding senior author on reasonable request.

\section{Author contributions}

Conceptualization, G.L. and R.A.; data curation, P.P.; formal analysis, P.P.; methodology, G.L., P.P. and R.A.; supervision, R.A.; writing-original draft, G.L., B.J.K. and R.A.; preparation of tables, G.L., B.J.K. and P.P.; writing-review and editing, BJK en R.A.; project administration, P.P. and R.A. All authors have read and agreed to the published version of the manuscript.

\section{Funding}


This project was co-financed by the European Regional Development Fund (GINOP-2.3.2-15-2016-00005), as well as by the Hungarian Academy of Sciences (TK2016-78). Project no. 135784 has also been implemented with the support provided by the National Research, Development, and Innovation Fund of Hungary, financed under the K_20 funding scheme. P.P. is a recipient of a fellowship from the ÚNKP-21-4 New National Excellence Program of the Ministry for Innovation and Technology from the source of the National Research, Development and Innovation Fund.

\section{Competing interests}

The authors declare no competing interests.

\section{References}

1. European Commission. Health Status of the Roma Population. Data Collection in the Member States of the European Union; European Commission: Brussels, Belgium, 978-92-79-37904-8 (2014).

2. Kosa, Z., et al. A comparative health survey of the inhabitants of Roma settlements in Hungary. Am. J. Public. Health. 97, 853-859 (2007).

3. Crowe DM. A History of the Gypsies of Eastern Europe and Russia. London, England: I.B. Tauris Publishers (1995).

4. McKee, M., Adany, R. \& MacLehose, L. Health status and trends in candidate countries. In: McKee, M., MacLehose, L., Nolte, E., eds. Health Policy and European Union Enlargement. Maidenhead, England: Open University Press; 24-42. European Observatory on Health Systems and Policies Series (2004).

5. Zoon, I. On the Margins: Roma and Public Services in Romania, Bulgaria, and Macedonia. New York, NY: Open Society Institute (2001).

6. Koupilova, I., Epstein, H., Holcik, J., Hajioff, S. \& McKee, M. Health needs of the Roma population in the Czech and Slovak Republics. Soc. Sci. Med. 53, 1191-1204 (2001).

7. Kosa, K., Lenart, B. \& Adany, R. Health status of the Roma population in Hungary [in Hungarian]. Orv. Hetil. 143, 2419-2426 (2002).

8. Hajioff, S. \& McKee, M. The health of the Roma people: a review of the published literature. J. Epidemiol. Community Health. 54, 864-869 (2000).

9. Oroszi, B., et al. Unequal burden of COVID-19 in Hungary: a geographical and socioeconomic analysis of the second wave of the pandemic. BMJ Glob. Health. 6, e006427. https://doi: 10.1136/bmjgh-2021-006427 (2021).

10. Piko, P., Kosa, Z., Sandor, J. \& Adany, R. Comparative risk assessment for the development of cardiovascular diseases in the Hungarian general and Roma population. Sci. Rep. 4, 11:3085. https://doi: 10.1038/s41598-021-82689-0 (2021).

11. Vincze, F. et al. Prevalence of Chronic Diseases and Activity-Limiting Disability among Roma and Non-Roma People: A Cross-Sectional, Census-Based Investigation. Int. J. Environ. Res. Public. Health. 16, 3620. doi: 10.3390/ijerph16193620 (2019). 
12. Sandor, J., et al. Healthcare Utilization and All-Cause Premature Mortality in Hungarian Segregated Roma Settlements: Evaluation of Specific Indicators in a Cross-Sectional Study. Int. J. Environ. Res. Public Health. 15, 1835. doi: 10.3390/ijerph15091835 (2018).

13. Adany R. Roma health is global ill health. Eur. J. Public Health. 24, 702-3. doi: 10.1093/eurpub/cku143 (2014).

14. La Parra, D., Gil-González, D., Jiménez, A. Social exclusion processes and the health status of the Roma people in Spain. Gac. Sanit. 27, 385-6 (2013).

15. LaParra Casado, D. Gil González, D. \& de la Torre Esteve, M. The Social Class Gradient in Health in Spain and the Health Status of the Spanish Roma. Ethn. Health 21, 468-479 (2016).

16. Font-Porterias, N., Giménez, A., Carballo-Mesa, A., Calafell, F. \& Comas, D. Admixture Has Shaped Romani Genetic Diversity in Clinically Relevant Variants. Front. Genet. 12, 683880. doi: 10.3389/fgene.2021.683880 (2021).

17. World Health Organization (WHO). Universal Eye Health. A Global Action Plan. Available at: http://www.who.int/blindness/actionplan (2013).

18. Chou, K.L. Combined effect of vision and hearing impairment on depression in older adults: Evidence from the English Longitudinal Study of Ageing. J. Affect. Disord. 106,191-6 (2008).

19. Lopez, D. et al. Falls, injuries from falls, health related quality of life and mortality in older adults with vision and hearing impairment-Is there a gender difference? Maturitas 69, 359-64 (2008).

20. World Health Organization (WHO). World report on disability. Available at: http://www.who.int/disabilities/world_report/2011/en/ (2011).

21. Scase, MO. \& Johnson MRD. Visual impairment in ethnic minorities in the UK. Int. Congr. Ser. 1282, 438-42 (2005).

22. Burkemper, B., Torres, M., Jiang, X., McKean-Cowdin, R. \& Varma R. Factors Associated with Visual Impairment in Chinese American Adults: The Chinese American Eye Study. Ophthalmic Epidemiol. 26, 329-335 (2019).

23. Fisher, D.E. et al. Visual Impairment in White, Chinese, Black, and Hispanic Participants from the Multi-Ethnic Study of Atherosclerosis Cohort. Ophthalmic Epidemiol. 22, 321-32 (2015).

24. Latorre-Arteaga, S., Gil-González, D., Vives-Cases, C. \& La Parra Casado, D. Vision and Hearing Health Inequities in the Roma population: A National Cross-Sectional Study in Spain. J. Immigr. Minor Health. 19,1304-1314 (2017).

25. Kahanec, M. Roma integration in European labor markets. IZA World of Labor: 39 https://doi: 10.15185/izawol.39 (2014).

26. Eurofound. Tackling labour shortages in EU Member States, Publications Office of the European Union, Luxembourg. Available at: https://www.eurofound.europa.eu/publications/report/2021/tackling-labour-shortages-in-eumember-states (2021). 
27. Kosa, K., Darago, L.; Adany, R. Environmental survey of segregated habitats of Roma in Hungary: a way to be empowering and reliable in minority research. Eur. J. Public Health. 21, 463-468. https://doi:10.1093/eurpub/ckp097 (2011).

28. Adany, R. et al. Prevalence of Insulin Resistance in the Hungarian General and Roma Populations as Defined by Using Data Generated in a Complex Health (Interview and Examination) Survey. Int. J. Environ. Res. Public Health. 4, 17:4833 (2020).

29. Széles, G. et al. A preliminary evaluation of a health monitoring programme in Hungary. Eur. J. Public Health. 15, 26-32. doi: 10.1093/eurpub/cki107 (2005).

30. International Diabetes Federation. The IDF Consensus Worldwide Definition of the Metabolic Syndrome. International Diabetes Federation; Brussels, Belgium: 2006.

31. Mountjoy, E., et al. Education and myopia: assessing the direction of causality by mendelian randomisation BMJ. 361, k2022 (2018).

32. Klein, AP. et al. Heritability analysis of spherical equivalent, axial length, corneal curvature, and anterior chamber depth in the Beaver Dam Eye Study. Arch. Ophthalmol. 127, 649-55 (2009).

33. Young T.L., Metlapally, R. \& Shay, A.E. Complex trait genetics of refractive error. Arch Ophthalmol. 125, 38-48 (2007).

34. Ferak, V., Sivakova, D. \& Sieglova, Z. Slovenski Cigani (Romovia)--populacia s najvyssim koeficientom inbridingu $v$ Europe [The Slovak gypsies (Romany)-a population with the highest coefficient of inbreeding in Europe]. Bratisl. Lek. Listy. 87,168-75 (1987).

35. Assal, S., Susanszky, E., Czeizel, A. High consanguinity rate in Hungarian gipsy communities. Acta Paediatr. Hung. 31, 299-304 (1991).

36. Font-Porterias, N., et al. European Roma groups show complex West Eurasian admixture footprints and a common South Asian genetic origin. PLoS Genet 15(9): e1008417. https://doi.org/10.1371/journal.pgen.1008417 (2019).

37. Balogh, I., Poka, R., Losonczy, G. \& Muszbek, L. High frequency of factor V Leiden mutation and prothrombin 20210A variant in Romanies of Eastern Hungary. Thromb. Haemost. 82, 1555-6 (1999).

38. Piko, P., Fiatal, S., Kosa, Z., Sandor, J. \& Adany, R. Genetic factors exist behind the high prevalence of reduced high-density lipoprotein cholesterol levels in the Roma population. Atherosclerosis. 263, 119-126. https://doi: 10.1016/j.atherosclerosis.2017.05.028 (2017).

39. Fiatal, S., Piko, P., Kosa, Z., Sandor, J. \& Adany, R. Genetic profiling revealed an increased risk of venous thrombosis in the Hungarian Roma population. Thromb. Res. 179, 37-44. https://doi: 10.1016/j.thromres.2019.04.031 (2019).

40. Soltesz, B. et al. The genetic risk for hypertension is lower among the Hungarian Roma population compared to the general population. PLoS One. 15, e0234547. https://doi:10.1371/journal.pone.0234547 (2020).

41. Kosa, Z. et al. Prevalence of metabolic syndrome among Roma: a comparative health examination survey in Hungary. Eur. J. Public Health. 25, 299-304. https://doi: 10.1093/eurpub/cku157 (2015). 
42. Piko P. et al. Changes in the Prevalence of Metabolic Syndrome, Its Components, and Relevant Preventive Medication between 2011 and 2018 in the Northeast Hungarian Roma Population. J. Pers. Med. 11, 595 (2021).

43. Sándor, J. et al. Delivery of cardio-metabolic preventive services to Hungarian Roma of different socio-economic strata. Fam. Pract. 34, 83-89 (2017).

44. Werissa, N.A. et al. SNP-Based Genetic Risk Score Modeling Suggests No Increased Genetic Susceptibility of the Roma Population to Type 2 Diabetes Mellitus. Genes (Basel). 10, 942. https://doi:10.3390/genes10110942 (2019).

45. Kovacs, N. et al. The impact of general practitioners' gender on process indicators in Hungarian primary healthcare: a nation-wide cross-sectional study. BMJ Open. 9, e027296. https://doi:10.1136/bmjopen-2018-027296 (2019). 